\title{
Molecular characterization of a Han Chinese family with essential hypertension
}

\author{
J.F. Zhu, X. Zhang and L. Ling \\ Zhengzhou, China \\ Corresponding author: J.F. Zhu \\ E-mail: zhujif@yeah.net \\ Genet. Mol. Res. 15 (2): gmr.15028084 \\ Received November 18, 2015 \\ Accepted January 7, 2016 \\ Published May 13, 2016 \\ DOI http://dx.doi.org/10.4238/gmr.15028084
}

Cardiology Department, First Affiliated Hospital of Zhengzhou University,

\begin{abstract}
Mutations in the mitochondrial genome have been found to be associated with essential hypertension. Here, we report the clinical and molecular characterization of a three-generation Han Chinese family with maternally inherited hypertension. Most strikingly, this pedigree exhibited a high penetrance of hypertension. Sequence analysis of the mitochondrial genome showed the presence of a homoplasmic T16189C mutation in the D-loop and the intergenic CO2/tRNA ${ }^{\text {Lys }}$ 9-bp common deletion, as well as a set of polymorphisms belonging to the East Asia haplogroup B5b1. The well-known T16189C mutation, which is in the first hypervariable segment of the mitochondrial control region, is implicated to be associated with a wide range of clinical disorders. Moreover, the genetic polymorphism 9-bp common deletion is found to be associated with hepatocellular carcinoma in the Han Chinese population. Thus, the combination of T16189C mutation and the 9-bp deletion may have caused mitochondrial dysfunction and contributed to the development of essential hypertension in this Chinese family.
\end{abstract}

Key words: Hypertension; mtDNA; Mutation; Chinese family 


\section{INTRODUCTION}

Essential hypertension (EH, MIM 145500) is a major public health problem and is a significant risk factor for heart attacks, stroke, and end-stage renal disease (He and Whelton, 1997; Hajjar et al., 2006). EH is commonly regarded as a multifactorial disease influenced by both genetic and environmental factors. Familial aggregation of high blood pressure, despite different environmental factors, suggests that genetic factors are involved in the etiology of hypertension (Zinner et al., 1971; Havlik and Feinleib, 1982). In fact, human hypertension is a condition associated with endothelial dysfunction and oxidative stress (Romero and Reckelhoff, 1999). Mitochondrial dysfunction has been implicated in both human and experimental hypertension. Moreover, maternal transmission of EH had been implicated in some pedigrees, indicating that mutations in mitochondrial DNA (mtDNA) are one of the molecular bases for this disorder (Watson et al., 2001; Wilson et al., 2004). It is generally believed that mutations in mtDNA may cause mitochondrial dysfunction; consequently, an inefficient metabolism caused by mitochondrial dysfunctions in skeletal and vascular smooth muscles may lead to the elevation of systolic blood pressure and, therefore, may be involved in the development of hypertension (Wisløff et al., 2005).

In order to understand the molecular mechanism underlying maternally transmitted $\mathrm{EH}$, we performed a systematic and extensive mutational screening for mtDNA mutations in the Zhengzhou City of Henan Province. Here, we describe a Chinese family with high penetrance of EH. Sequence analysis of the mitochondrial genome showed the occurrence of T16189C and 9-bp deletion. We also briefly discuss the molecular pathogenesis of these mutations in hypertension.

\section{MATERIAL AND METHODS}

\section{Subjects}

As part of a genetic screening program for hypertension, a Han Chinese family (Figure 1) was ascertained at the Hypertension Clinic of the First Affiliated Hospital of Zhengzhou University. Informed consent, blood samples, and clinical evaluations were obtained from all participating family members, under the protocols approved by the Ethics Committee of Zhengzhou University. Members of this family were interviewed and evaluated to identify both personal or medical histories of hypertension and other clinical abnormalities.

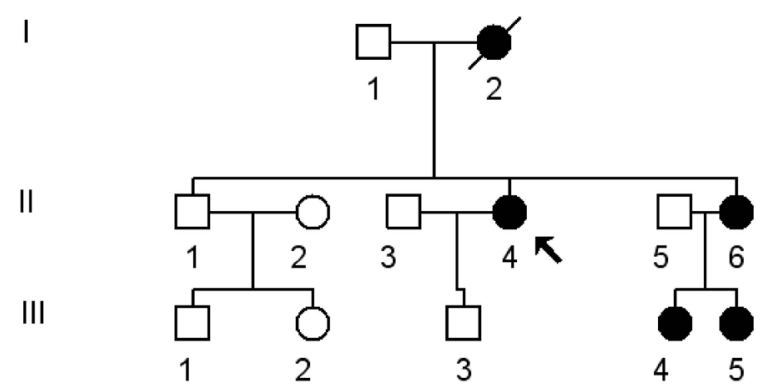

Figure 1. Han Chinese family with essential hypertension; hypertensive individuals are indicated by filled symbols, and arrow denotes the proband. 


\section{Clinical evaluation}

Members of this Chinese family underwent a physical examination and laboratory assessment of cardiovascular disease risk factors. A physician measured the systolic and diastolic blood pressures of the subjects using a mercury column sphygmomanometer and a standard protocol. The first and the fifth Korotkoff sounds were taken to be indicative of systolic and diastolic blood pressure, respectively. Hypertension was diagnosed according to the recommendation of the Joint National Committee on Detection, Evaluation and Treatment of High Blood Pressure and the World Health Organization-International Society of Hypertension, with a systolic blood pressure of $\geq 140 \mathrm{mmHg}$ and/or a diastolic blood pressure of $\geq 90 \mathrm{mmHg}$.

\section{Mutational screening for mtDNA}

Genomic DNA was isolated from whole blood cells of the participants using Puregene DNA Isolation Kits (Gentra Systems, Minneapolis, MN, USA). The entire mitochondrial genome of the proband (II-4) was PCR amplified in 24 overlapping fragments by using sets of the lightstrand and heavy-strand oligonucleotide primers, as described previously (Rieder et al., 1998). Each fragment was purified and subsequently analyzed by direct sequencing in an ABI 3700 automated DNA sequencer (Applied Biosystems, Foster City, CA, USA) using the Big Dye Terminator Cycle sequencing reaction kit. In addition, 250 healthy individuals from the same

area were obtained as controls. The resultant sequence data were compared with the revised consensus Cambridge sequence (GenBank accession No. NC_012920) (Andrews et al., 1999).

\section{Phylogenetic and haplogroup analyses}

A total of 17 vertebrate mtDNA sequences were used for the inter-specific analysis. The conservation index was then calculated by comparing the human nucleotide variants with 16 other vertebrates. For haplogroup classification, the entire mtDNA sequences of the proband (II-4) were assigned to the East Asia mitochondrial phylogenetic tree, as described elsewhere (Kong et al., 2006).

\section{RESULTS}

\section{Clinical features of the Chinese family with essential hypertension}

The proband (II-4) is a 65-year-old woman who came from the Zhengzhou City of Henan Province. She went to the Department of Cardiology in the First Affiliated Hospital, Zhengzhou University for treatment of hypertension. Her blood pressure was 145/90 mmHg. Physical examination, laboratory assessment of cardiovascular disease risk factors, and routine electrocardiography showed no other clinical abnormalities, including diabetes mellitus, vision loss, deafness, and other neurological disorders. The clinical characterizations of the affected members in this family are listed in Table 1.

\section{Mutational analysis of the mitochondrial genome}

The maternally transmitted pattern of hypertension in this pedigree suggested the 
involvement of the mitochondrial genome and led us to analyze the mtDNA mutations in matrilineal relatives. We performed PCR amplifications of the mitochondrial genome and subsequently sequenced the PCR fragments from the proband (II-4), as well as the matrilineal relatives (II-6, III-4, III-5). As shown in Table 2, a total of 22 variants were identified. Of these, six variants were in the D-loop, four variants were in the $12 \mathrm{~S}$ rRNA gene, three variants were in the $16 \mathrm{~S}$ rRNA gene, eight variants were in mitochondrial protein coding genes, and one variant was in the intergenic CO2/tRNA ${ }^{\text {Lys }}$ region. Most of the single nucleotide polymorphisms were wellknown mutational hot spots and none of these variants could be defined as "novel" (Bandelt et al., 2009). The variants in rRNA and polypeptides were further evaluated by phylogenetic analysis and sequenced from other organisms including mouse (Bibb et al., 1981), bovine (Gadaleta et al., 1989), and Xenopus laevis (Roe et al., 1985). Besides the D-loop T16189C mutation and the intergenic $\mathrm{CO} 2 / \mathrm{tRNA}^{\mathrm{Lys}}$ 9-bp deletion, none of other variants showed evolutionary conservation nor implicated to have functional consequences.

Table 1. Clinical characterization of the members in this family with essential hypertension.

\begin{tabular}{l|l|c|c|c|c}
\hline Subjects & Gender & Age of onset (year) & Age at test (year) & Systolic pressure $(\mathrm{mmHg})$ & Diastolic pressure $(\mathrm{mmHg})$ \\
\hline II-4 & Female & 60 & 65 & 145 & 90 \\
\hline II-6 & Female & 65 & 68 & 150 & 85 \\
\hline III-4 & Female & 38 & 40 & 140 & 95 \\
\hline III-5 & Female & 36 & 42 & 130 & 100 \\
\hline
\end{tabular}

Table 2. Complete mtDNA variants in this Chinese family.

\begin{tabular}{|c|c|c|c|c|}
\hline Gene & Position & Replacement & Conservation $(\mathrm{H} / \mathrm{B} / \mathrm{M} / \mathrm{X})^{*}$ & Previously reported \\
\hline \multirow[t]{6}{*}{ D-loop } & 16189 & T to $\mathrm{C}$ & & Yes \\
\hline & 16213 & $\mathrm{G}$ to $\mathrm{A}$ & & Yes \\
\hline & 16217 & $\mathrm{~T}$ to $\mathrm{C}$ & & Yes \\
\hline & 16295 & $\mathrm{C}$ to $\mathrm{T}$ & & Yes \\
\hline & 16299 & A to $\mathrm{G}$ & & Yes \\
\hline & 16519 & $\mathrm{~T}$ to $\mathrm{C}$ & & Yes \\
\hline \multirow[t]{4}{*}{ 12S rRNA } & 709 & $\mathrm{G}$ to $\mathrm{A}$ & G/A/A/- & Yes \\
\hline & 750 & A to $\mathrm{G}$ & $\mathrm{A} / \mathrm{A} / \mathrm{A} /-$ & Yes \\
\hline & 1422 & Del G & & Yes \\
\hline & 1438 & A to $\mathrm{G}$ & $\mathrm{A} / \mathrm{A} / \mathrm{A} / \mathrm{G}$ & Yes \\
\hline \multirow[t]{3}{*}{ 16S rRNA } & 2706 & A to $\mathrm{G}$ & $\mathrm{A} / \mathrm{G} / \mathrm{A} / \mathrm{A}$ & Yes \\
\hline & 3107 & $\mathrm{~T}$ to $\mathrm{C}$ & & Yes \\
\hline & 3209 & A to $\mathrm{T}$ & & Yes \\
\hline ND2 & 4769 & A to $\mathrm{G}$ & & Yes \\
\hline \multirow[t]{2}{*}{$\mathrm{CO} 1$} & 5465 & $\mathrm{~T}$ to $\mathrm{C}$ & & Yes \\
\hline & 7028 & $\mathrm{C}$ to $\mathrm{T}$ & & Yes \\
\hline NC7 & $8281-8289$ & Del CCCCCTCTA & $\mathrm{T} / \mathrm{S} / \mathrm{L} / \mathrm{Q}$ & Yes \\
\hline ATP8 & 8860 & A to $G(T h r$ to Ala) & $\mathrm{T} / \mathrm{A} / \mathrm{A} / \mathrm{T}$ & Yes \\
\hline $\mathrm{CO} 3$ & 9123 & $\mathrm{G}$ to $\mathrm{A}$ & & Yes \\
\hline ND4 & 11719 & $\mathrm{G}$ to $\mathrm{A}$ & & Yes \\
\hline \multirow[t]{2}{*}{ Cytb } & 14751 & $\mathrm{C}$ to $\mathrm{T}$ & & Yes \\
\hline & 14766 & $\mathrm{C}$ to $\mathrm{T}$ (Thr to Ile) & & Yes \\
\hline
\end{tabular}

*Conservation of amino acid for polypeptides of nucleotides for rRNAs in human (H), bovine (B), mouse (M), and Xenopus laevis (X).

\section{DISCUSSION}

In this study, we have performed clinical, genetic, and molecular characterization of a Han Chinese family with high penetrance of essential hypertension. Hypertension as a sole 
clinical phenotype was only presented in matrilineal relatives, suggesting that mutations in mtDNA were the molecular bases of this disorder. Clinical and genetic evaluation of this family indicated variable severity and age onset in hypertension. In particular, the age of onset ranged from 36 to 60 years, with an average of 50 years. Moreover, matrilineal relatives in this family had an earlier age of onset of hypertension, suggesting that mitochondrial sequence variants may be a risk factor in early molecular diagnosis and detection.

Sequence analysis of the complete mitochondrial genome identified 22 polymorphisms belonging to the human mitochondrial haplogroup B5b1 (Kong et al., 2006). Of these, the homoplasmic D-loop T16189C mutation and the CO2/tRNA ${ }^{\text {Lys }}$ 9-bp deletion were of special interest. The T16189C mutation was in the first hypervariable segment of human mtDNA control region that contains many control elements for transcription and replication and was an important area of interaction of mtDNA with nuclear-encoded proteins (Wallace, 2015). The T-to-C transition at 16189 generated an uninterrupted homopolymeric C-tract that was highly unstable and caused heteroplastic length variation of mtDNA by replication slippage. Preliminary data suggest that the T16189C mutation resulted in a modest reduction in mtDNA copy number compared with nuclear DNA, which might have a mildly detrimental effect on respiratory chain function in beta cells. Moreover, mtDNA T16189C mutation mapped precisely to a novel point of origin of mtDNA replication (OriB), which made it likely that the mutation would alter mtDNA function (Yasukawa et al., 2005). Therefore, the critical position of the $\mathrm{T} 16189 \mathrm{C}$ mutation in the mitochondrial genome suggested that the mutation might have a direct role in the pathogenesis of essential hypertension in this family.

The 9-bp (CCCCCTCTA) common deletion in the small non-coding segment located between the $\mathrm{CO} 2$ and tRNA ${ }^{\mathrm{Lys}}$ gene had been used as a genetic marker to trace descent from people of East Asian origin (Yao et al., 2000). This deletion has also been suggested to be associated with several other diseases including cancer (Krishnan and Turnbull, 2010; Zhuo et al., 2010; Komandur et al., 2011). Due to its specific location, the 9-bp deletion may have the potential to alter downstream and upstream gene expression. A recent study identified that this deletion may create binding sites for hsa-miR-519c-5p and hsa-miR-526a; thus, this deletion may be involved in the pathogenesis of hepatocellular carcinoma (Jin et al., 2012). Similarly, this 9-bp deletion may also be associated with EH. Taken together, the combination of the D-loop T16189C mutation and the CO2/tRNA ${ }^{\text {Lys }}$ 9-bp deletion may contribute to the high penetrance of EH in this Han Chinese family.

\section{Conflicts of interest}

The authors declare no conflict of interest.

\section{ACKNOWLEDGMENTS}

Research supported by the key project from the universities of Henan Province (\#16A320027).

\section{REFERENCES}

Andrews RM, Kubacka I, Chinnery PF, Lightowlers RN, et al. (1999). Reanalysis and revision of the Cambridge reference sequence for human mitochondrial DNA. Nat. Genet. 23: 147.http://dx.doi.org/10.1038/13779 
Bandelt HJ, Salas A, Taylor RW and Yao YG (2009). Exaggerated status of "novel" and "pathogenic" mtDNA sequence variants due to inadequate database searches. Hum. Mutat. 30: 191-196. http://dx.doi.org/10.1002/humu.20846

Bibb MJ, Van Etten RA, Wright CT, Walberg MW, et al. (1981). Sequence and gene organization of mouse mitochondrial DNA. Cell 26: 167-180. http://dx.doi.org/10.1016/0092-8674(81)90300-7

Gadaleta G, Pepe G, De Candia G, Quagliariello C, et al. (1989). The complete nucleotide sequence of the Rattus norvegicus mitochondrial genome: cryptic signals revealed by comparative analysis between vertebrates. J. Mol. Evol. 28: 497-516. http://dx.doi.org/10.1007/BF02602930

Hajjar I, Kotchen JM and Kotchen TA (2006). Hypertension: trends in prevalence, incidence, and control. Annu. Rev. Public Health 27: 465-490.http://dx.doi.org/10.1146/annurev.publhealth.27.021405.102132

Havlik RJ and Feinleib M (1982). Epidemiology and genetics of hypertension. Hypertension 4: III121-III127. http:// dx.doi.org/10.1161/01.HYP.4.5 Pt 2.III121

He J and Whelton PK (1997). Epidemiology and prevention of hypertension. Med. Clin. North Am. 81: 1077-1097. http:// dx.doi.org/10.1016/S0025-7125(05)70568-X

Jin Y, Yu Q, Zhou D, Chen L, et al. (2012). The mitochondrial DNA 9-bp deletion polymorphism is a risk factor for hepatocellular carcinoma in the Chinese population. Genet. Test. Mol. Biomarkers 16: 330-334. http://dx.doi. org/10.1089/gtmb.2011.0208

Komandur S, Venkatasubramanian S, Alluri RV, Rao P, et al. (2011). Mitochondrial insertion-deletion polymorphism: role in disease pathology. Genet. Test. Mol. Biomarkers 15: 361-364. http://dx.doi.org/10.1089/gtmb.2010.0205

Kong QP, Bandelt HJ, Sun C, Yao YG, et al. (2006). Updating the East Asian mtDNA phylogeny: a prerequisite for the identification of pathogenic mutations. Hum. Mol. Genet. 15: 2076-2086. http://dx.doi.org/10.1093/hmg/ddl130

Krishnan KJ and Turnbull DM (2010). Mitochondrial DNA and genetic disease. Essays Biochem. 47: 139-151. http:// dx.doi.org/10.1042/bse0470139

Rieder MJ, Taylor SL, Tobe VO and Nickerson DA (1998). Automating the identification of DNA variations using quality-based fluorescence re-sequencing: analysis of the human mitochondrial genome. Nucleic Acids Res. 26: 967973. http://dx.doi.org/10.1093/nar/26.4.967

Roe BA, Ma DP, Wilson RK and Wong JF (1985). The complete nucleotide sequence of the Xenopus laevis mitochondrial genome. J. Biol. Chem. 260: 9759-9774.

Romero JC and Reckelhoff JF (1999). State-of-the-Art lecture. Role of angiotensin and oxidative stress in essential hypertension. Hypertension 34: 943-949. http://dx.doi.org/10.1161/01.HYP.34.4.943

Wallace DC (2015). Mitochondrial DNA variation in human radiation and disease. Cell 163: 33-38. http://dx.doi. org/10.1016/j.cell.2015.08.067

Watson B, Jr., Khan MA, Desmond RA and Bergman S (2001). Mitochondrial DNA mutations in black Americans with hypertension-associated end-stage renal disease. Am. J. Kidney Dis. 38: 529-536. http://dx.doi.org/10.1053/ ajkd.2001.26848

Wilson FH, Hariri A, Farhi A, Zhao H, et al. (2004). A cluster of metabolic defects caused by mutation in a mitochondrial tRNA. Science 306: 1190-1194. http://dx.doi.org/10.1126/science.1102521

Wisløff U, Najjar SM, Ellingsen O, Haram PM, et al. (2005). Cardiovascular risk factors emerge after artificial selection for low aerobic capacity. Science 307: 418-420. http://dx.doi.org/10.1126/science.1108177

Yao YG, Watkins WS and Zhang YP (2000). Evolutionary history of the mtDNA 9-bp deletion in Chinese populations and its relevance to the peopling of east and southeast Asia. Hum. Genet. 107: 504-512. http://dx.doi.org/10.1007/ $\underline{\mathrm{s} 004390000403}$

Yasukawa T, Yang MY, Jacobs HT and Holt IJ (2005). A bidirectional origin of replication maps to the major noncoding region of human mitochondrial DNA. Mol. Cell 18: 651-662.http://dx.doi.org/10.1016/j.molcel.2005.05.002

Zhuo G, Feng G, Leng J, Yu L, et al. (2010). A 9-bp deletion homoplasmy in women with polycystic ovary syndrome revealed by mitochondrial genome-mutation screen. Biochem. Genet. 48: 157-163. http://dx.doi.org/10.1007/ s10528-009-9308-5

Zinner SH, Levy PS and Kass EH (1971). Familial aggregation of blood pressure in childhood. N. Engl. J. Med. 284: 401404. http://dx.doi.org/10.1056/NEJM197102252840801 